\title{
Colonic Granular Cell Tumor: An Endoscopic and Histopathologic Review with Case Illustration
}

\author{
Daryl Ramai ${ }^{1}$, Jonathan Lai ${ }^{2}$, Kinesh Changela ${ }^{1}$, Sury Anand ${ }^{3}$ \\ 1. Division of Gastroenterology and Hepatology, Academic Affiliate of the Icahn School of Medicine, \\ Clinical Affiliate of the Mount Sinai Hospital 2. School of Medicine, St. George's University, Grenada, \\ West Indies 3. Division of Gastroenterology, NYU Langone Hospital, 150 55th St Brooklyn, Ny, 11220.
}

$\square$ Corresponding author: Daryl Ramai,dramai@sgu.edu

Disclosures can be found in Additional Information at the end of the article

\section{Abstract}

Granular cell tumors (GCTs) are rare and benign tumors that can occur at any anatomical site. GCTs are thought to originate from nerve cells, particularly Schwann cells. Their name derives from the fact that an accumulation of cytoplasmic lysosomes imparts the tumor with a granular appearance. They are most commonly observed in the oral cavity, skin and subcutaneous tissue, breast, and respiratory tract. Granular cell tumors rarely affect the gastrointestinal tract. We report a 58-year-old female with a past medical history of hypertension, mitral valve prolapse, and depression who presented for surveillance colonoscopy. A single firm sessile polypoid lesion, with overlying pale tan color mucosa, measuring approximately 1 to $1.5 \mathrm{~cm}$, was found in the ascending colon. Biopsy of the nodule followed by histopathology was positive for S100 and CD68, but negative for AE1/AE3, CD117, smooth muscle actin, and desmin, consistent with the diagnosis of GCT. We review the clinicopathologic features of GCTs.

Categories: Gastroenterology

Keywords: granular cell tumor, colon, gastrointestinal tract, schwann cells

\section{Introduction}

Granular cell tumors (GCTs) are rare and benign tumors that can occur along any anatomical site. GCTs are thought to originate from nerve cells, particularly Schwann cells [1]. Their name derives from the fact that an accumulation of cytoplasmic lysosomes imparts the tumor with a granular appearance. They are most commonly found in the oral cavity (40\%), skin and subcutaneous tissue (30\%), breast (15\%), and respiratory tract (15\%). Gastrointestinal GCTs are rare (8\%), and predominantly affect the esophagus, followed by the stomach and duodenum [2]. Of all colonic GCTs, approximately $86 \%$ arise in the ascending colon, with GCTs of the rectum being the rarest [2]. Though GCTs can present at any age, its peak incidence occurs in the fourth and sixth decades of life, with a slight female predilection.

\section{Case Presentation}

A 58-year-old African-American female with a past medical history of hypertension, mitral valve prolapse, and depression presented for surveillance colonoscopy. Vital signs showed the heart rate at $72 \mathrm{bpm}$, temperature $98.3^{\circ} \mathrm{F}$, respiratory rate $14 \mathrm{bpm}$, and blood pressure 134/73 mmHg. Her physical exam was unremarkable, and she denied alcohol consumption, smoking, or drug use. Laboratory findings showed hemoglobin $11.9 \mathrm{~g} / \mathrm{dL}$, hematocrit 38\%, white blood count 4.6 x $103 \mathrm{~K} / \mu \mathrm{L}$, and platelet 136 x $103 \mathrm{~K} / \mu \mathrm{L}$. Diagnostic colonoscopy revealed a single 


\section{Cureus}

firm sessile polypoid lesion with overlying pale tan color mucosa, measuring approximately 1 to $1.5 \mathrm{~cm}$ in the ascending colon (Figure 1). The polyp was completely removed by hot snare cautery polypectomy. Histopathology was positive for S100 and CD68 but negative for AE1/AE3, CD117, smooth muscle actin, and desmin, consistent with the diagnosis of GCT (Figure 2).

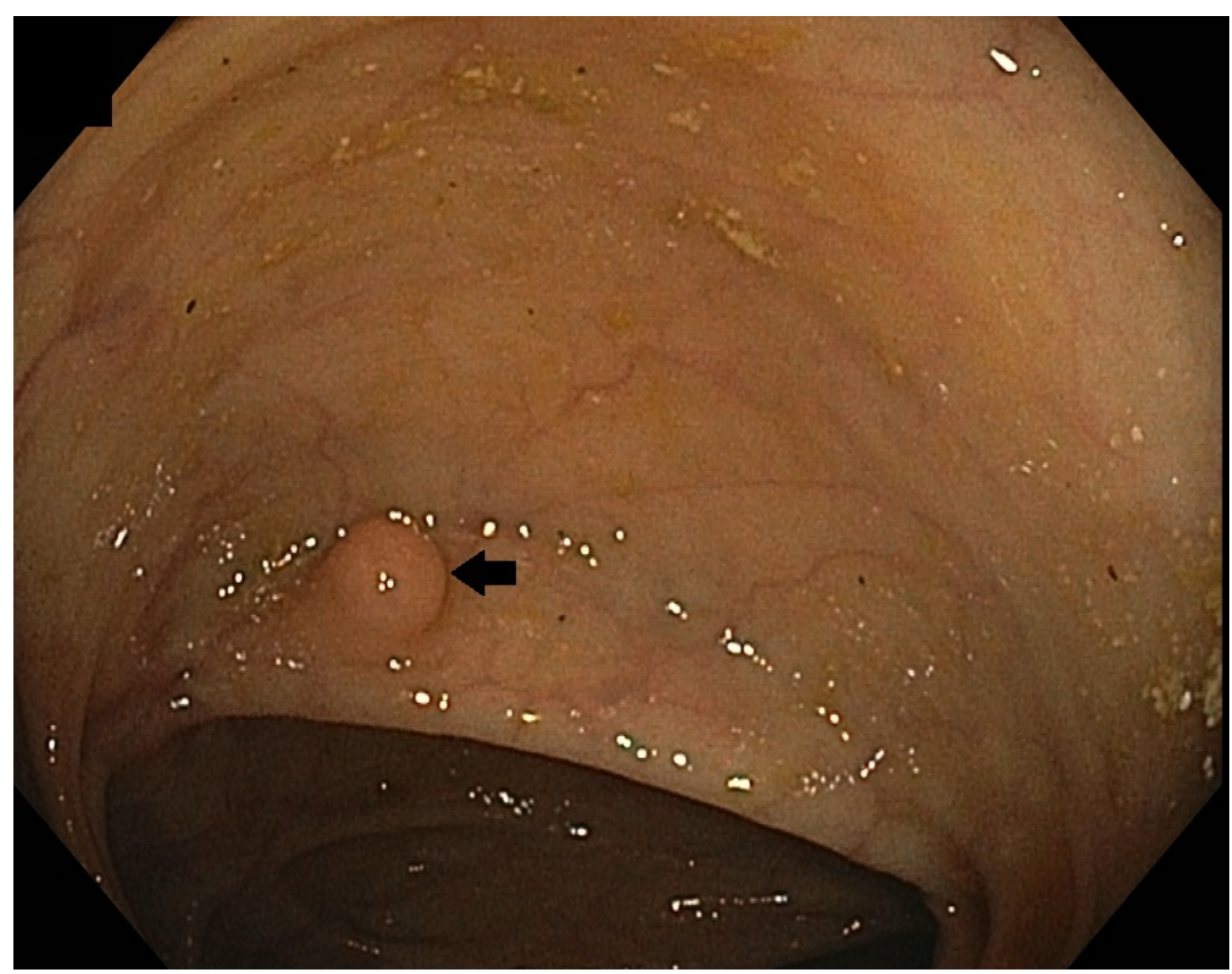

FIGURE 1: Solitary polyp, measuring 1 to $2 \mathrm{~cm}$ and covered by normal-appearing mucosa, was found in the ascending colon
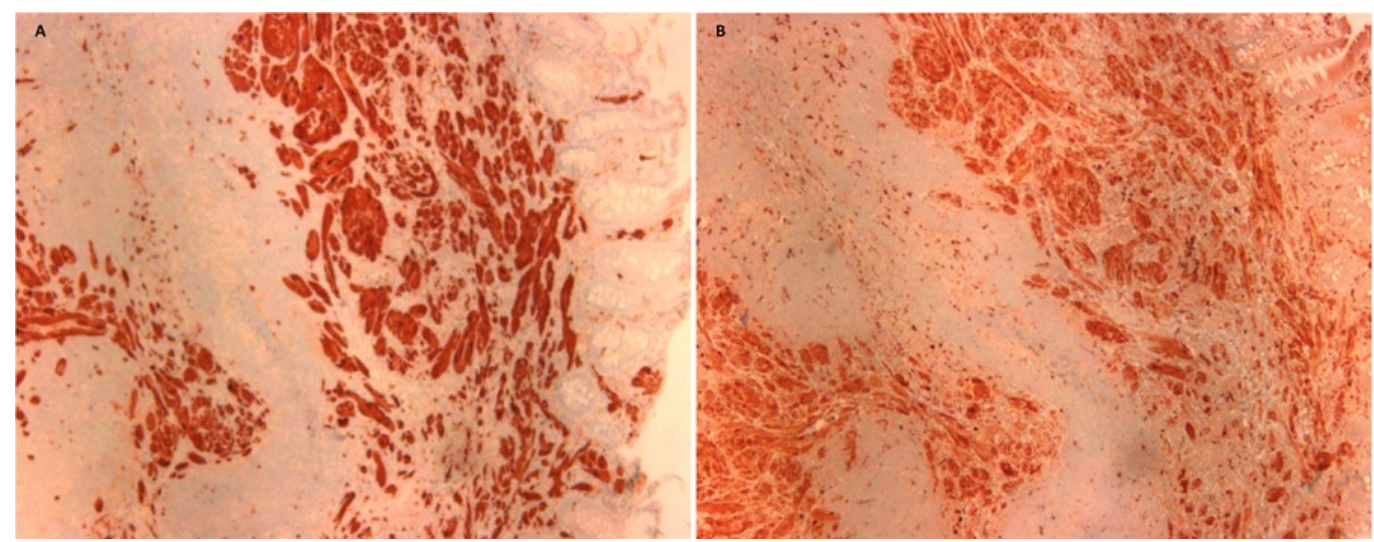

\section{FIGURE 2: Histopathology of nodule}

A) Tumor cells showing $\mathrm{S} 100$ cytoplasmic immunoreactivity (x40); B) Tumor cells with CD68 immunoreactivity (x40) 


\section{Discussion}

Granular cell tumor (GCT), also known as granular cell myoblastoma or Abrikossof's tumor, is a benign proliferation of Schwan cells of soft tissues [3]. It was first described by the Russian pathologist, Alexei Ivanovich Abrikossoff, in 1926 [3]. GCTs were initially thought to be myogenic tumors; however, studies have favored a Schwann cell origin. While GCTs may occur at any anatomical location, gastrointestinal tract GCTs are rare. Most cases involve the skin, subcutaneous tissue, and oral cavity. In the GI tract, GCTs are more commonly found in the esophagus, while the cecum and rectum are rarely affected [4].

Gastrointestinal GCTs are typically solitary and represent an incidental finding on screening colonoscopy. Additionally, these polyps are painless, nonulcerated, and firm. Although most case reports highlight that GCTs are benign neoplasms, some cases of malignancy have been reported in the literature, representing less than $2 \%$ of all GCTs [5-6]. Additionally, GCTs must be differentiated from other neoplasms, including stromal, carcinoid, and smooth muscle tumors. To this end, GCTs are rarely diagnosed based on macroscopic or endoscopic appearance, particularly due to its small size and shape, resembling a diminutive polyp [6]. In the present case, it was difficult to suspect GCT as the endoscopic features of the tumor resembled those of a small sessile polyp. We performed a one-stage endoscopic snare polypectomy during the screening colonoscopy.

The diagnosis of GCT is confirmed by histopathology and includes (1) plump histiocyte-like, bland-looking neoplastic cells with abundant granular eosinophilic cytoplasms containing acidophilic, periodic acid Schiff (PAS) stain-positive, diastase-resistant granules, (2) small, uniform nuclei in which mitotic figures are absent, and (3) neural markers, including S-100 protein or neuron-specific enolase (NSE), expressed uniformly [7-9]. In the present case, histological findings on the resected specimen were consistent with the diagnosis of GCT. Morphological criteria for malignant GCT include (1) spindling of tumor cells, (2) increased nuclear to cytoplasmic ratio, (3) pleomorphism, (4) necrosis, (5) vesicular nuclei with large nucleoli, and (6) increased mitotic activity (> 2 mitoses per 10 high-powered fields). FanburgSmith, et al. reported that if three of the six morphological criteria listed above were present, the lesion was most likely malignant [10].

Malignancy has been found to correlate with tumor size. Approximately more than $60 \%$ of metastatic GCTs were larger than $4 \mathrm{~cm}$ in diameter $[6,10]$. However, in most colonic GCTs, the tumor size was less than $2 \mathrm{~cm}$ and the tumor was well separated from the muscularis propia. Since this tumor is considered to be usually benign, endoscopic resection has become the gold standard in the management of gastrointestinal GCTs.

\section{Conclusions}

We report a case of GCT located in the ascending colon. The tumor was removed by endoscopic resection, and the patient was discharged without any complications. Clinicians should bear in mind the differential diagnosis of GCT when presented with submucosal colonic polyps. Additionally, endoscopists should be aware of the pathological characteristics associated with malignant GCTs in order to provide early diagnosis and treatment.

\section{Additional Information Disclosures}

Human subjects: Consent was obtained by all participants in this study. Conflicts of interest: In compliance with the ICMJE uniform disclosure form, all authors declare the following:

Payment/services info: All authors have declared that no financial support was received from 
any organization for the submitted work. Financial relationships: All authors have declared that they have no financial relationships at present or within the previous three years with any organizations that might have an interest in the submitted work. Other relationships: All authors have declared that there are no other relationships or activities that could appear to have influenced the submitted work.

\section{References}

1. Fisher ER, Wechsler H: Granular cell myoblastoma - a misnomer. Electron microscopic and histochemical evidence concerning its Schwann cell derivation and nature (granular cell schwannoma). Cancer. 1962, 15:936-54. 10.1002/1097-0142(196209/10)15:5<936::AIDCNCR2820150509>3.0.CO;2-F

2. Sunkara T, Nagaraj SV, Gaduputi V: Granular cell tumor of rectum: a very rare entity . Case Rep Gastrointest Med. 2017, 2017:3795482. 10.1155/2017/3795482

3. Abrikossoff A: Myomas originating from transversely striated voluntary musculature [Article in German]. Virchows Arch Pathol Anat. 1926, 260:215-33. 10.1007/BF02078314

4. Lack EE, Worsham GF, Callihan MD, et al.: Granular cell tumor: a clinicopathologic study of 110 patients. J Surg Oncol. 1980, 13:301-16. 10.1002/jso.2930130405

5. Ordóñez NG, Mackay B: Granular cell tumor: a review of the pathology and histogenesis . Ultrastruct Pathol. 1999, 23:207-22. 10.1080/019131299281545

6. Sohn DK, Choi HS, Chang YS, et al.: Granular cell tumor of colon: Report of a case and review of literature. World J Gastroenterol. 2004, 10:2452-54.

7. Zhang M, Sun ZQ, Zou XP: Cytologic findings in granular cell tumors, with emphasis on the diagnosis of malignant granular cell tumor by fine-needle aspiration biopsy. Oncol Lett. 2014, 8:551-55. 10.3892/ol.2014.2152

8. Miettinen M, Lehtonen E, Lehtola $\mathrm{H}$, et al.: Histogenesis of granular cell tumour - an immunohistochemical and ultrastructural study. J Pathol. 1984, 142:221-29.

10.1002/path.1711420309

9. Parfitt JR, McLean CA, Joseph MG, et al.: Granular cell tumours of the gastrointestinal tract: expression of nestin and clinicopathological evaluation of 11 patients. Histopathology. 2006, 48:424-30. 10.1111/j.1365-2559.2006.02352.x

10. Fanburg-Smith JC, Meis-Kindblom JM, Fante R, Kindblom LG: Malignant granular cell tumor of soft tissue: diagnostic criteria and clinicopathologic correlation. Am J Surg Pathol. 1998, 22:779-94. 10.1097/00000478-199807000-00001 